\title{
Derivation of four computable 24-hour pediatric sepsis phenotypes to facilitate personalized enrollment in early precise anti-inflammatory clinical trials
}

Yidi Qin MS. ${ }^{1}$; Kate F. Kernan MD. ${ }^{2}$; Zhenjiang Fan BS. ${ }^{3}$; Hyun-Jung Park PhD. ${ }^{1}$; Soyeon Kim PhD. ${ }^{4}$ : Scott W. Canna, MD. ${ }^{4}$; John A Kellum, MD. ${ }^{2}$; Robert A. Berg, MD. ${ }^{5}$; David Wessel, MD. ${ }^{6}$; Murray M. Pollack, MD. ${ }^{6}$; Kathleen Meert, MD. ; Mark Hall, MD. ${ }^{8}$; Christopher Newth, MD. ${ }^{9}$; John C. Lin, MD. ${ }^{10}$; Allan Doctor, MD. ${ }^{10}$; Tom Shanley, MD. ${ }^{12}$; Tim Cornell, MD. ${ }^{13}$; Rick E. Harrison, MD, ${ }^{11}$; Athena F. Zuppa, MD. ${ }^{4}$; Russell Banks, MS. ${ }^{12}$; Ron W. Reeder, PhD. ${ }^{12}$; Richard Holubkov, PhD. ${ }^{12}$; Daniel A. Notterman, MD, PhD. ${ }^{13}$; J. Michael Dean, MD. ${ }^{12}$; and Joseph A. Carcillo, MD. ${ }^{2}$ on behalf of the Eunice Kennedy Shriver National Institute of Child Health and Human Development Collaborative Pediatric Critical Care Research Network

${ }^{1}$ Graduate School of Public Health, University of Pittsburgh, Pittsburgh, PA. ${ }^{2}$ Division of Pediatric Critical Care Medicine, Department of Critical Care Medicine, Children's Hospital of Pittsburgh, Center for Critical Care Nephrology and Clinical Research Investigation and Systems Modeling of Acute Illness Center, University of Pittsburgh, Pittsburgh, PA., ${ }^{3}$ Department of Computer Sciences, University of Pittsburgh, Pittsburgh PA. ${ }^{4}$ Department of Pediatrics,

University of Pittsburgh, Pittsburgh, PA., ${ }^{5}$ Department of Anesthesiology, Children's Hospital of Philadelphia, Philadelphia, PA. ${ }^{6}$ Division of Critical Care Medicine, Department of Pediatrics, Children's National Hospital, Washington, DC., ${ }^{7}$ Division of Critical Care Medicine, Department of Pediatrics, Children's Hospital of Michigan, Detroit, MI, Central Michigan University Mt. Pleasant, MI, ${ }^{8}$ Division of Critical Care Medicine, Department of Pediatrics, The Research Institute at Nationwide Children's Hospital Immune Surveillance Laboratory, and Nationwide Children's Hospital, Columbus, OH., ${ }^{9}$ Division of Critical Care Medicine, 
Department of Anesthesiology and Critical Care Medicine, Children's Hospital Los Angeles, Los Angeles, CA., ${ }^{10}$ Division of Critical Care Medicine, Department of Pediatrics, St. Louis Children's Hospital, St. Louis, MO., ${ }^{11}$ Division of Critical Care Medicine, Department of Pediatrics, C. S. Mott Children's Hospital, Ann Arbor, MI., ${ }^{12}$ Division of Critical Care Medicine, Department of Pediatrics, Mattel Children's Hospital at University of California Los Angeles, Los Angeles, CA., ${ }^{13}$ University of Utah, Salt Lake City, UT, ${ }^{14}$ Princeton University, Princeton, NJ.

Word Count $-3,112$

Supplemental digital content is available for this manuscript

Supported, in part, by grant R01GM108618 (to Dr Carcillo PI, Dr. Park, Dr Canna, and Dr Kellum) from the National Institutes of General Medical Sciences, by 5U01HD049934- 10S1 (to Dr Carcillo) and K12HD047349 (to Dr Kernan) from the Eunice Kennedy Shriver National Institutes of Child Health and Human Development, National Institutes of Health, Department of Health and Human Services and the following cooperative agreements: U10HD049983, U10HD050096, U10HD049981, U10HD063108, U10HD63106, U10HD063114, U10HD050012, and U01HD049934.

Conflicts of Interest and Source of Funding

Drs. Carcillo's, Berg's, Wessel's, Pollack's, Meert's, Hall's, Doctor's, Cornell's, Harrison's, Zuppa's, Reeder's, Banks's, and Holubkov's institutions received funding from the National Institutes of Health (NIH). Drs. Carcillo's, Newth's, Shanley’s, and Dean's institutions received 
funding from the National Institutes of Child Health and Human Development. Drs. Carcillo, Berg, Wessel, Polack, Meert, Hall, Newth, Doctor, Shanley, Cornell, Harrison, Zuppa, Reeder, Banks, Holubkov, Notterman, and Dean received support for article research from the NIH. Dr. Carcillo's institution also received funding from the National Institutes of General Medical Sciences. Dr. Pollack disclosed that his research is supported by philanthropy from Mallinckrodt Pharmaceuticals. Dr. Hall received funding from Bristol Myers-Squibb (for service on an advisory board) and LaJolla Pharmaceuticals (service as a consultant), both unrelated to the current submission. Dr. Newth received funding from Philips Research North America. Dr. Doctor's institution received funding from the Department of Defense and Kalocyte. Dr. Shanley received funding from Springer publishing, International Pediatric Research Foundation, and Pediatric Academic Societies. Dr. Cornell disclosed he is co-founder of Pre-Dixon Bio. Dr. Holubkov received funding from Pfizer (Data Safety Monitoring Board [DSMB] member), Medimmune (DSMB member), Physicians Committee for Responsible Medicine (biostatistical consulting), DURECT Corporation (biostatistical consulting), Armaron Bio (DSMB past member), and St Jude Medical (DSMB past member). The remaining authors have disclosed that they do not have any potential conflicts of interest.

For information regarding this article, Joseph A Carcillo MD

Suite 2000, Faculty Pavilion, UPMC Children's Hospital of Pittsburgh, 4400 Penn Avenue

Pittsburgh, PA 15421

Telephone 412-692-6737

FAX 412-692-6076

E-mail: carcilloja@ccm.upmc.edu or 


\begin{abstract}
Objective: Thrombotic microangiopathy induced Thrombocytopenia Associated Multiple Organ Failure and hyperinflammatory Macrophage Activation Syndrome are important causes of late pediatric sepsis mortality that are often missed or have delayed diagnosis. Our objective is to derive computable 24-hour sepsis phenotypes to facilitate enrollment in early precise antiinflammatory trials targeting mortality from these conditions.
\end{abstract}

Design: Machine learning analysis using consensus k-means clustering.

Setting: Nine pediatric intensive care units.

Patients: 404 children with severe sepsis.

Interventions: 24-hour computable phenotypes derived using 25 bedside variables including Creactive protein and ferritin.

Measurements and Main Results: Four computable phenotypes (PedSep-A, B, C, and D) are derived. Compared to the overall population mean, PedSep-A has the least inflammation (median C-reactive protein $7.3 \mathrm{mg} / \mathrm{dL}$, ferritin $125 \mathrm{ng} / \mathrm{mL}$ ), younger age, less chronic illness, and more respiratory failure $(\mathrm{n}=135 ; 2 \%$ mortality); PedSep-B (median C-reactive protein 13.2 $\mathrm{mg} / \mathrm{dL}$, ferritin $225 \mathrm{ng} / \mathrm{mL}$ ) has organ failure with intubated respiratory failure, shock, and Glasgow Coma Scale score $<7$ ( $\mathrm{n}=102,12 \%$ mortality); PedSep-C (median C-reactive protein $15.2 \mathrm{mg} / \mathrm{dL}$, ferritin $405 \mathrm{ng} / \mathrm{mL}$ ) has elevated ferritin, lymphopenia, more shock, more hepatic failure and less respiratory failure $(n=110$; mortality 10\%); and, PedSep D (median C-reactive protein $13.1 \mathrm{mg} / \mathrm{dL}$ ferritin $610 \mathrm{ng} / \mathrm{mL}$ ), has hyperferritinemic, thrombocytopenic multiple organ failure with more cardiovascular, respiratory, hepatic, renal, hematologic, and neurologic system failures $(\mathrm{n}=56,34 \%$ mortality). PedSep-D has highest likelihood of Thrombocytopenia 
medRxiv preprint doi: https://doi.org/10.1101/2021.12.02.21267016; this version posted December 6, 2021. The copyright holder for this preprint (which was not certified by peer review) is the author/funder, who has granted medRxiv a license to display the preprint in perpetuity.

All rights reserved. No reuse allowed without permission.

Associated Multiple Organ Failure (Adj OR 47.51 95\% CI [18.83-136.83], p < 0.0001) and Macrophage Activation Syndrome (Adj OR 38.63 95\% CI [13.26-137.75], p <0.0001), and an observed survivor interaction with combined methylprednisolone and intravenous immunoglobulin therapies $(\mathrm{p}<0.05)$.

CONCLUSIONS AND RELEVANCE: Machine learning identifies four computable phenotypes (www.pedsepsis.pitt.edu). Membership in PedSep-D appears optimal for enrollment in early anti-inflammatory trials targeting Thrombocytopenia Associated Multiple Organ Failure and Macrophage Activation Syndrome.

Word Count 300

Keywords - severe sepsis, multiple organ failure, immunoparalysis associated multiple organ failure, thrombocytopenia associated multiple organ failure, macrophage activation syndrome, sequential multiple organ failure, hyperferritinemic sepsis 


\section{Author's Comment}

Question Can machine learning methods derive 24-hour computable pediatric sepsis phenotypes that facilitate early identification of patients for enrollment in precise antiinflammatory therapy trials?

Findings Four distinct phenotypes (PedSep-A, B, C, and D) were derived by assessing 25 bedside clinical variables in 404 children with sepsis. PedSep-D patients had a thrombotic microangiopathy and hyperinflammatory macrophage activation biomarker response, and improved survival odds associated with combined methylprednisolone plus intravenous immunoglobulin therapy.

Meaning Four novel computable 24-hour phenotypes are identifiable (www.pedsepsis.pitt.edu) that could potentially facilitate enrollment in early precise antiinflammatory trials targeting thrombotic microangiopathy and macrophage activation in pediatric sepsis. 


\section{Introduction}

Severe sepsis defined by infection and organ failure contributes to 1 of 5 deaths globally, with over half occurring in children (1). Many of these deaths occur with multiple organ failure (MOF) $(2,3)$ independent from timely shock resuscitation $(4,5)$, implying that dysregulated host immune activation could be targetable in the pediatric intensive care unit (PICU). Among such conditions are immune depression leading to Immunoparalysis associated MOF (IPMOF) $(6,7,13,14)$, thrombotic microangiopathy leading to Thrombocytopenia Associated MOF (TAMOF) $(8,9,13,14)$, and hyperinflammatory Macrophage Activation Syndrome (MAS) driven either by uncontrolled lymphoproliferation manifest as sequential liver failure associated MOF (SMOF) $(10,13,14)$ or by macrophage activation without lymphoproliferation manifest as combined hepatobiliary dysfunction and disseminated intravascular coagulation $(11,12,13,14)$. In the PHENOtyping pediatric sepsis induced Multiple organ failure Study (PHENOMS) (14) we previously reported that these conditions developed at a median of day 3 to 7 of sepsis, with TAMOF and MAS demonstrating 46\% mortality, and IPMOF 16\% mortality (14). Antiinflammatory therapies used to reverse TAMOF and MAS include methylprednisolone, intravenous immunoglobulin (IVIG), and plasma exchange $(8,15-18)$.

Our clinical trials challenge is to identify these at-risk children for early enrollment when therapies have their greatest likelihood to succeed. The NIGMS sepsis research working group recommendations call for use of new clinical research approaches in extant clinical data sets (https://loop.nigms.nih.gov/2019/05/recommendations) to characterize septic patients and improve the efficiency of early trials of new sepsis treatments. In this manuscript we use machine learning methods in our extant data set from PHENOMS (14) to derive 24-hour computable sepsis phenotypes based on available bedside clinical variables including C-reactive 
protein and ferritin (19-21). Our specific goals are to determine 1) if computable 24-hour phenotypes show different risks for development of TAMOF and MAS; and 2) if administration of methylprednisolone, IVIG, and/or plasma exchange by bedside clinicians was associated with survivor interaction in the computable phenotype most likely to develop TAMOF and MAS.

\section{Materials and Methods Overview}

We analyzed blood samples and clinical data obtained from our previously published PHENOMS study (14). Approval was obtained from The University of Utah Institutional Review Board, Central IRB \# 70976. Written informed consent was obtained from one or more parents/guardians for each child. Assent was garnered when the child was able. Patients were enrolled from 2015-2017. The CONSORT diagram and details of the clinical study protocol have been previously published (14). Three consented and enrolled children who were excluded from reporting in the parent study manuscript because there was a cap of 81 patients to maximize equalization in enrollment among the centers, are additionally included in this machine learning manuscript. In brief, children qualified for enrollment in PHENOMS if they 1) were between the ages of 44 weeks gestation to 18 years of age; 2) were suspected of having infection meeting two or more of four systemic inflammatory response criteria (22); and 3) had one or more organ failures (23).

DeMerle et al suggests that machine learning phenotypes need to be clinically relevant, biologically plausible, nonsynonymous, treatment responsive, and reproducible if they are to provide a 'path forward' in trial design (24). Our statistical approach is shown in eFigure 1. To derive nonsynonymous computable phenotypes, we applied unsupervised clustering methods (25) to clinical and laboratory data available at the first 24 hours of PICU stay with severe sepsis (Table 1, Figure 1, eTables 1-4, eFigures 2-7). To understand biological plausibility and clinical 
relevance we examined correlations between the phenotypes and inflammatory cytokine responses (Figure 2, eTables 5 and 6, eFigure 8); and organ failure and mortality outcomes (Table 2, eTables 7-9, eFigures 9-12). We further assessed development of Immunoparalysis associated MOF (immune depression defined by ex vivo TNF response to endotoxin $<200 \mathrm{pg} / \mathrm{ml}$ beyond three days with two or more organ failures) $(7,14,26)$, Thrombocytopenia associated MOF (thrombotic microangiopathy defined by ADAMTS13 activity $<57 \%$ of control with platelet count $<100,000 / \mathrm{mm}^{3}$ and acute kidney injury with oliguria and serum creatinine $>1$ mg/dL) (8,14,26), Sequential Liver Failure associated MOF (lymphoproliferative disease associated with liver failure defined by soluble FAS Ligand $>200 \mathrm{pg} / \mathrm{mL}$ with $\mathrm{PaO} 2 / \mathrm{FiO} 2<300$ and mechanical ventilation followed seven days or later with serum ALT $>100 \mathrm{U} / \mathrm{L}$ and bilirubin $>1 \mathrm{mg} / \mathrm{dL})(10,14,26)$ and Macrophage Activation Syndrome (hyperinflammation defined by ferritin $>500 \mathrm{ng} / \mathrm{mL}$ with platelet count $<100 \mathrm{~K} / \mathrm{mm} 3$, INR $>1.5$, ALT $>100 \mathrm{U} / \mathrm{L}$ and bilirubin $>1 \mathrm{mg} / \mathrm{dL})$ (Table 2, eTable 7, eFig 13) $(11,12,14,26)$.

In an exploratory analysis of treatment interactions in the phenotypes, we applied elastic net regression analysis to any organ support and anti-inflammatory therapies used by bedside clinicians that were found in univariable analysis to be associated with survival in any of the computable phenotypes or in the population as a whole $(\mathrm{p}<0.05)($ Figure 3 , eTables $10,11,12$ eFigure 14) (27). Confirmatory logistic regression analysis was performed on anti-inflammatory therapies associated with survivor odds ratio $>10$ in the elastic net regression model (eTable 12).

\section{Candidate Clinical Variables for Phenotyping}

Of the 52 bedside variables collected in the parent study, only 25 were available at 24 hours with less than $20 \%$ missingness and less than $60 \%$ correlation with any other variable (Table 1, eTable 1). These included demographic variables (age, gender, ethnicity, previous 
health status, post-op status), PRISM related vital signs and laboratory values (systolic blood pressure, heart rate, Glasgow Coma Scale score, hemoglobin, creatinine, platelet count, intubation status), markers of inflammation (temperature, number of SIRS criteria, lymphocyte count, C-reactive protein level, ferritin level), and organ failures (Central Nervous System $=$ Glasgow Coma Scale $<12$ not explained by use of sedation; Cardiovascular $=$ Requirement for vasoactive agents for Systolic Blood Pressure $<5$ th percentile for age; Respiratory $=\mathrm{PaO} 2 / \mathrm{FiO} 2$ ratio $<300$ requiring mechanical ventilation; Renal $=$ oliguria and serum creatinine $>1 \mathrm{mg} / \mathrm{dL}$; Hepatic $=$ ALT $>100$ and Bilirubin $>1 \mathrm{mg} / \mathrm{dL}$; Hematologic $=$ Platelet Count $<100 \mathrm{~K}$ and INR $>1.5)(10,14,26)$. For each PRISM variable we extracted the most abnormal value in the first 6 hours. For each inflammation and organ failure variable we extracted the most abnormal value within 24 hours.

\section{Biological Correlates and Outcomes}

We studied 33 biomarkers including 31 cytokines and two functional assays; whole blood ex vivo TNF response to endotoxin as a marker of immune depression $(6,7,14,26)$, and ADAMTS 13 activity as a marker of microvascular thrombosis in the presence of thrombocytopenia $(6,14,26)$. Plasma for cytokine measurement was divided into three assays. IL18, IL-18BP, and CXCL9 were measured at 25-fold dilution (28). IFN $\alpha$, sCD163, and IL-22 were measured by Bioplex inflammatory flex-set assay per manufacturer's instructions (BioRad). The remainder were measured by Bioplex Group I/II flex-set assay (Bio-Rad). All cytokines were measured on a BioPlex 200 System (Bio-Rad). The functional assays were measured as previously described $(6,7,8,14,26)$.

The primary outcome was hospital mortality. Secondary outcomes included development of new or progressive MOF defined as development of new organ failure(s) after day one (2); 
length of stay in the PICU; subsequent development of Immunoparalysis $(7,8,14,26)$,

Thrombocytopenia associated MOF $(8,14,26)$, Sequential liver failure associated MOF $(10,14,26)$, and Macrophage Activation Syndrome $(11,12,14,26)$; as well as use of mechanical ventilation, and extracorporeal therapies.

Adjusted odds ratios controlling for age, sex, ethnicity, race, and total PRISM score, were calculated for primary and selected secondary outcomes. For summary analyses the threshold for statistical significance was less than 0.05 for two - sided tests after adjustment for multiple testing. All analyses were performed with R version 3.6.2.

\section{Results}

\section{Derivation of Clinical Sepsis Phenotypes}

The consensus k-means clustering models were used because the method provides nonsynonomous agnostic clusters and has a 1,000 iterations step to assure internal consistency (19). We found a 4-class model was the optimal fit, with phenotypes we named PedSep-A, B, C and $\mathrm{D}$ (eFigure 4). Consensus matrix plots and the relative change under cumulative distribution function curve implied little statistical gain by increasing to a 5 or 6 class model, with penalty of overfitting. The size and characteristics of the 4-class model appear in Table 1 and Figure 1. They ranged in size (from 14\% to $34 \%$ of the cohort) and differed in clinical characteristics and organ dysfunction patterns (Table 1, eTable 3, Figure 1, eFigures 5 and 9). With the exception of the SIRS criteria number, the other 24 variables differed among the phenotypes. Compared to all other phenotypes PedSep-A patients were younger and previously healthy, with the lowest CRP and ferritin levels, the highest lymphocyte and platelet counts, highest heart rate, and lowest creatinine; PedSep-B patients were most likely to be intubated and had the lowest Glasgow 
Coma Scale Score; PedSep C patients had the highest temperature and Glasgow Coma Scale score, least pulmonary failure, and lowest lymphocyte count; and PedSep-D patients had the highest creatinine and number of organ failures, including renal, hepatic, and hematologic organ failure, with the lowest platelet count. On average, PedSep-B and D patients had multiple organ failure whereas PedSep-A and C patients did not. Ferritin levels were highest in PedSep-C and PedSep-D distinguishing them from PedSep-A and B (Table 1, eTable 3, eFigures 5 and 9)

\section{Correlation of Phenotypes with Biomarker Profiles}

The inflammatory biomarker profiles differed across the four computable phenotypes. Inflammation (as evidenced by cytokine signature) increased and immune response (whole blood ex vivo TNF response to endotoxin) and coagulation function (ADAMTS13 activity) decreased going across PedSep-A, B, C, and D (Tables 5 and 6, Figure 2, eFigure 8). PedSep-A showed the least inflammation with the lowest M-CSF, IL-8, IL-6, sCD163, MCP1/CCL2, ferritin, Creactive protein, IL-10, IL-22, and MIP $1 \alpha$ levels overall; lower IL-17a and IP10/CXCL10 than PedSep-C; and lower IL-18 and IL2Ra than PedSep-D. PedSep-A had the best immune and coagulation function with normal whole blood ex vivo TNF response to endotoxin $(>200$ $\mathrm{pg} / \mathrm{mL}$ ) and ADAMTS 13 activity. In contrast PedSep-D had the most profound inflammatory response with highest M-CSF, IL-8, SCF, sCD163, IL-16, IL-10, TNF, and MIP1 $\alpha$ levels; and thrombotic microangiopathic response with lowest ADAMTS 13 activity decreased to $<57 \%$ of control with thrombocytopenia. Consistent with this increased inflammation response the macrophage inhibitor TRAIL was reduced in PedSep-D compared to PedSep-C.

\section{Relationship with Infection, Organ Support Needs, and Hospital Mortality}


PedSep-A had more viral infections, PedSep-B had more pneumonia, and PedSep-C and D had more blood infections. Patients in PedSep-C had the least mechanical ventilation and the shortest length of stay. Patients in PedSep-D required more extracorporeal membrane oxygenation than in PedSep-A, and the most continuous renal replacement therapy (CRRT) overall. PedSep-A patients required the least CRRT (Table 2, eTable 7).

Hospital mortality was 2\% in PedSep-A, 12\% in PedSep-B, 10\% in PedSep-C, and 34\% in PedSep-D (PedSep B vs A Adj OR 4.11 95\% CI [1.11-19.96] p=0.048; PedSep C vs A Adj OR 4.35 95\% CI [1.23-20.43] $\mathrm{p}=0.034$; PedSep D vs A Adj OR 17.25 95\% CI [4.93-92.06] $\mathrm{p}=$ 4.42E-05; PedSep D vs B Adj OR 4.20 95\%CI [1.84-9.97] p=0.0008; and PedSep D vs C Adj OR $3.9795 \%$ CI 1.62-10.14] p = 0.003) (Table 2, eTable 7).

The mortality curves show all deaths in PedSep-A occurred before seven days; whereas, deaths in PedSep-B, C, and D continued to accrue after seven days (eFigure 10). Mortality was associated with Glasgow Coma Scale score $<12$, decreased TNF and IL-2Ra levels, and increased MCP3 levels in PedSep-A; increased IL-6, IL-8, and MCP1/CCL2 levels in PedSepB; high ferritin, lymphopenia, lower temperature, higher blood pressure, and increased IL-8 levels in PedSep-C; and, hyperferritinemia, chronic illness, increased MIP-1 $\alpha$, IL-8, and IL-10 levels, and decreased IL-18 and sFASL levels in PedSep-D (eTables 8 and 9, eFigure 11 and 12).

\section{Relationship with Development of Immunoparalysis, TAMOF, SMOF, and MAS}

On average, children in PedSep-A and PedSep-C developed less than two organ failures; children in PedSep-B developed more than two organ failures; and children in PedSep-D developed more than three organ failures over 28 days (eFigure 10). Children in PedSep-D had the highest proclivity to develop Immunoparalysis (Adj OR 2.40 95\% CI [1.25-4.53; p = 7.20E- 
03), new and progressive organ failure (Adj OR 4.03 95\% CI [2.19-7.55]; $\mathrm{p}=9.48 \mathrm{E}-06$ ),

Thrombocytopenia associated MOF (Adj OR 47.51 95\% CI [18.83-136.83]; $\mathrm{p}=1.25 \mathrm{E}-14$ ),

Sequential liver failure associated MOF (Adj OR 61.56 95\% CI [8.93-1,282.58]; p = 3.80E-04), and Macrophage Activation Syndrome (Adj OR 38.63 95\% CI [13.26-137.75]; p=4.61E-10).

Immunoparalysis and Thrombocytopenia associated MOF also occurred more commonly in children in PedSep-B and D compared to those in PedSep-A (Table 2, eFigure 13).

\section{Heterogeneous treatment interactions with use of anti-inflammatory therapies}

All 3 organ support therapies, and 11 of 41 anti-inflammatory therapies were associated with outcome in univariable analysis (eTable 10 and 11) and included in the exploratory elastic net regression analysis (Figure 3, eFig 14) (27). This was not performed in PedSep-A because mortality was very low at $2 \%$. The constructed elastic net regression heatmaps visualize heterogeneous survival association patterns across PedSep-B, C, and D (Figure 3). Survivor odds ratios $>10$-fold with use of anti-inflammatory agents were only observed in PedSep-D, in those patients receiving combined corticosteroids plus IVIG, and in extracorporeal membrane oxygenator patients receiving plasma exchange.

Logistic regression analysis confirmed a survivor interaction in PedSep D patients receiving methylprednisolone plus IVIG compared to either methylprednisone or IVIG alone (Methylprednisolone Adj OR 0.50 95\% CI [0.073-3.75] p = 0.47; IVIG Adj OR 0.16 95\% CI $[0.018-1.02] \mathrm{p}=0.07 ;$ Methylprednisolone + IVIG Adj OR = 35.13; 95\% CI [1.57-722.68] $\mathrm{p}=$ 0.042); and also a survivor interaction with use of combined methylprednisone + IVIG in PedSep D patients compared to PedSep B + C patients (PedSep-D vs B + C Adj OR = 0.19 95\% CI $[0.09-0.41] \mathrm{p}<0.001 ;$ Methylprednisolone + IVIG combination Adj OR $=0.22$ 95\% CI [0.06-0.89] $\mathrm{p}=0.022 ;$ PedSep-D * Methylprednisolone + IVIG combination Adj OR $=16.67$ 
$95 \% \mathrm{CI}[1.64-500] \mathrm{p}=0.029)$ indicating that the survival outcome interaction associated with this combination therapy is specific to PedSep-D (eFig 14). Logistic regression analysis was not statistically significant for combined ECMO and plasma exchange therapy (eTable 12).

\section{Discussion}

Machine learning analysis of our extant PHENOMS dataset identifies four computable 24-hour phenotypes meeting three of five 'path forward' criteria (24) providing impetus for further evaluation in new pediatric sepsis studies. The phenotypes demonstrated clinical relevance with differences in types of infections, organ failures, need for organ support therapies, outcomes, and proclivity to development of TAMOF and MAS. Consensus k-means clustering and t-SNE analyses demonstrated that the phenotypes are nonsynonymous. The differences in cytokine profiles provide biological plausibility for these phenotypes having different inflammation responses, highlighted in PedSep-D by decreased ADAMTS13 with TAMOF and increased MIP $1 \alpha$ with MAS. Exploratory modeling of treatment interactions with survival using elastic net regression showed a signal with combined methylprednisone plus IVIG therapy in PedSep D; however, wide confidence intervals in the confirmatory logistic regression analysis provides impetus for further evaluation in new studies. We are presently assessing treatment responsiveness and reproducibility in the ongoing 500 patient Second Argentinian Pediatric Sepsis Epidemiology Study (PI Roberto Jabornisky), and in the placebo arm of our NICHD network's ongoing 1,000 patient Personalized Immunomodulation in Pediatric Sepsis and Multiple Organ Dysfunction trial.

PedSep-A is characterized by younger previously healthy children with respiratory failure and the least increased inflammation. This resembles the adult $\alpha$ phenotype in the SENECA trial 
(19), and also the MARS 3 and sepsis response signature 2 endotypes, which found predominant expression of adaptive immune and B-cell developmental pathways (29-31). Mortality in PedSep-A was low at $2 \%$ and did not increase after 7 days, making anti-inflammatory clinical trials directed to survival less feasible.

PedSep-B is characterized by multiple organ failure requiring intubation for more severe respiratory failure, shock, and central nervous system dysfunction with increased C-reactive protein levels and $12 \%$ mortality. This is reminiscent of children reported in the Life After Pediatric Sepsis Evaluation study (32); the shock with hypoxia phenotype in adult sepsis induced MOF (33); and the severe hypoxia, altered mental status, and shock phenotype in pediatric MOF (34).

PedSep-C is distinguished by cardiovascular failure and relative absence of need for intubation, in the presence of elevated C-reactive protein, high ferritin, and lymphopenia, with $10 \%$ mortality. This is reminiscent of the Toxic Shock (TSS) - Kawasaki syndrome phenotype currently being considered as PMIS/MIS-C syndrome (35-39). Similar to TSS and Kawasaki's, our PedSep-C patients showed elevated IL-17a and IP10/CXCL10 levels (40-42).

PedSep-D patients had cardiovascular, respiratory, liver, renal, hematologic, and neurologic dysfunction with 34\% mortality; clinical features shared by the adult $\delta$ phenotype characterized in the SENECA study using electronic health record criteria for Sepsis-3 (19); the shock with thrombocytopenia pediatric MOF phenotype (34); and previously reported subclasses including the hyperinflammatory sub-phenotype reported in acute respiratory distress syndrome, a condition commonly related to sepsis $(43,44)$. It also resembles sepsis endotypes derived using transcriptomic analyses of circulating immune cells, specifically the inflammopathic cluster 
known as sepsis signature 1, or the Molecular Diagnosis and Risk Stratification of Sepsis [MARS] 2 cluster (29-31).

PedSep-D is specifically characterized by hyperferritinemic (ferritin $>500 \mathrm{ng} / \mathrm{mL}$ ), thrombocytopenic (platelet count $<100 \mathrm{~K}$ ) multiple organ failure with the highest likelihood of new and progressive multiple organ failure, accruing mortality after 7 days. PedSep-D membership identifies children with highest proclivity for decreased ADAMTS 13 activity with Thrombocytopenia Associated MOF, and increased MIP $1 \alpha$ with Macrophage Activation Syndrome. Methylprednisone and IVIG therapy have been associated with survival in hyperferritinemic, thrombocytopenic sepsis and macrophage activation syndrome $(15,16)$, and were reminiscently associated with a survivor interaction in PedSep-D.

Although the PHENOMS database is the largest available longitudinal multiple center pediatric sepsis induced MOF study with CRP and ferritin levels (14) it brings inherent limitations this machine learning analysis. Definitions of sepsis and organ failure are limited to those used in this parent study. Only 25 out of 52 available clinical and laboratory variables had $<20 \%$ missingness without covariance for inclusion in the derivation. Only 33 additional biomarkers $(7,8,10,26,45)$ were performed for assessment of biological plausibility. Survival interactions could only be assessed for the therapies given by bedside clinicians as part of their standard care of patients. Reproducibility cannot be addressed in one study.

\section{Conclusions}

Machine learning analysis of the PHENOMS database identifies four novel computable 24-hour pediatric sepsis phenotypes and provides a computable tool allowing clinical researchers to perform bedside identification of individual patient phenotype (www.pedsepsis.pitt.edu). 
medRxiv preprint doi: https://doi.org/10.1101/2021.12.02.21267016; this version posted December 6, 2021. The copyright holder for this preprint (which was not certified by peer review) is the author/funder, who has granted medRxiv a license to display the preprint in perpetuity.

All rights reserved. No reuse allowed without permission.

Among these, PedSep-D membership identifies children most likely to benefit from early enrollment in anti-inflammatory trials targeting Thrombocytopenia Associated MOF and Macrophage Activation Syndrome. Over the next five years, reproducibility will be assessed in two ongoing pediatric sepsis studies to determine whether this computable tool can be used in the future to improve the efficiency of early trials of new sepsis treatments targeting thrombotic microangiopathy and macrophage activation in children. 
ACKNOWLEDGMENTS Clinical Research Investigation and Systems Modeling of Acute illness center: Ali Smith, BS; Octavia Palmer, MD; Vanessa Jackson, AA; Renee Anderko, BS, MS. Children's Hospital of Pittsburgh: Jennifer Jones, RN; Luther Springs. Children's Hospital of Philadelphia: Carolanne Twelves, RN, BSN, CCRC; Mary Ann Diliberto, BS, RN, CCRC; Martha Sisko, BSN, RN, CCRC, MS; Pamela Diehl, BSN, RN; Janice Prodell, RN, BSN, CCRC; Jenny Bush, RNC, BSN; Kathryn Graham, BA; Kerry Costlow, BS; Sara Sanchez. Children's National Hospital: Elyse Tomanio, BSN, RN; Diane Hession, MSN, RN; Katherine Burke, BS. Children's Hospital of Michigan, Central Michigan University: Ann Pawluszka, RN, BSN; Melanie Lulic, BS. Nationwide Children's Hospital: Lisa Steele, RN, CCRC; Andrew R. Yates, MD; Josey Hensley, RN; Janet Cihla, RN; Jill Popelka, RN; Lisa Hanson-Huber, BS. Children’s Hospital Los Angeles and Mattel Children's Hospital: Jeni Kwok, JD; Amy Yamakawa, BS. Children's Hospital of Washington University of Saint Louis: Michelle Eaton, RN. Mott Children's Hospital: Frank Moler, MD; Chaandini Jayachandran, MS, CCRP. University of Utah Data Coordinating Center: Teresa Liu, MPH, CCRP; Jeri Burr, MS, RN-BC, CCRC, FACRP; Missy Ringwood, BS, CMC; Nael Abdelsamad, MD, CCRC; Whit Coleman, MSRA, BSN, RN, CCRC. 


\section{References}

1) Rudd KE, Johnson SC, Agesa KM, et al. Global, regional, and national sepsis incidence and mortality, 1990-2017: analysis for the Global Burden of Disease Study Lancet 2020; 395:200211

2) Lin JC, Spinella PC, Fitzgerald JC, et al. Sepsis Prevalence, Outcomes, and Therapy Study Investigators. New or Progressive Multiple Organ Dysfunction Syndrome in Pediatric Severe Sepsis: A Sepsis Phenotype with Higher Morbidity and Mortality. Pediatr Crit Care Med 2017;18:8-16

3) Weiss SL, Fitzgerald JC, Pappachan J, et al. Sepsis Prevalence, Outcomes, and Therapies (SPROUT) Study Investigators and Pediatric Acute Lung Injury and Sepsis Investigators (PALISI) Network. Global epidemiology of pediatric severe sepsis: the sepsis prevalence, outcomes, and therapies study. Am J Respir Crit Care Med 2015;191:1147-1157

4) Workman JK, Ames SG, Reeder RW, et al. Treatment of Pediatric Septic Shock With the Surviving Sepsis Campaign Guidelines and PICU Patient Outcomes. Pediatr Crit Care Med 2016;17: e451-e458

5) Evans IVR, Phillips GS, Alpern ER, et al. Association Between the New York Sepsis Care Mandate and In-Hospital Mortality for Pediatric Sepsis. JAMA 2018;320:358-367

6) Muszynski JA, Nofziger R, Moore-Clingenpeel M, et al. Early Immune Function and Duration of Organ Dysfunction in Critically III Children with Sepsis. Am J Respir Crit Care Med 2018;198:361-369 
7) Hall MW, Knatz NL, Vetterly C, et al. Immunoparalysis and nosocomial infection in children with multiple organ dysfunction syndrome. Intensive Care Med 2011;37:525-532

8)Nguyen TC, Han YY, Kiss JE, et al. Intensive plasma exchange increases a disintegrin and metalloprotease with thrombospondin motifs-13 activity and reverses organ dysfunction in children with thrombocytopenia-associated multiple organ failure. Crit Care Med 2008;36:28782887

9) Wong HR, Cvijanovich NZ, Anas N, et al. Pediatric Sepsis Biomarker Risk Model-II:

Redefining the Pediatric Sepsis Biomarker Risk Model With Septic Shock Phenotype. Crit Care Med 2016;44:2010-2017

10) Doughty L, Clark RS, Kaplan SS, Sasser H, Carcillo J. sFas and sFas ligand and pediatric sepsis-induced multiple organ failure syndrome. Pediatr Res 2002;52:922-927

11) Kyriazopoulou E, Leventogiannis K, Norrby-Teglund A, et al. Hellenic Sepsis Study Group Macrophage activation-like syndrome: an immunological entity associated with rapid progression to death in sepsis. BMC Med 2017;15:172

12) Shakoory B, Carcillo JA, Chatham WW, et al. Interleukin-1 Receptor Blockade Is Associated with Reduced Mortality in Sepsis Patients with Features of Macrophage Activation Syndrome: Reanalysis of a Prior Phase III Trial. Crit Care Med 2016;44:275-281

13) Carcillo JA, Podd B, Aneja R, et al. Pathophysiology of Pediatric Multiple Organ Dysfunction Syndrome. Pediatr Crit Care Med. 2017;18: S32-S45 
14) Carcillo JA, Berg RA, Wessel D, et al. A Multicenter Network Assessment of Three Inflammation Phenotypes in Pediatric Sepsis-Induced Multiple Organ Failure. Pediatr Crit Care Med 2019;20:1137-1146

15) Emmenegger U, Frey U, Reimers A, et al. Hyperferritinemia as indicator for intravenous immunoglobulin treatment in reactive macrophage activation syndromes. Am J Hematol $2001 ; 68: 4-10$

16)Demirkol D, Yildizdas D, Bayrakci B, et al. Hyperferritinemia in the critically ill child with secondary hemophagocytic lymphohistiocytosis/sepsis/multiple organ dysfunction syndrome/macrophage activation syndrome: what is the treatment? Crit Care 2012;16: R52

17) Sevketoglu E, Yildizdas D, Horoz OO, et al. Use of therapeutic plasma exchange in children with thrombocytopenia-associated multiple organ failure in the Turkish thrombocytopenia-associated multiple organ failure network. Pediatr Crit Care Med 2014;15: e354-359

18) Fortenberry JD, Nguyen T, Grunwell JR, et al. Therapeutic Plasma Exchange in Children With Thrombocytopenia-Associated Multiple Organ Failure: The Thrombocytopenia-Associated Multiple Organ Failure Network Prospective Experience. Thrombocytopenia-Associated Multiple Organ Failure (TAMOF) Network Study Group. Crit Care Med 2019;47: e173-e181

19) Seymour CW, Kennedy JN, Wang S, et al. Derivation, Validation, and Potential Treatment Implications of Novel Clinical Phenotypes for Sepsis. JAMA 2019;321:2003-2017

20) Taylor MD, Allada V, Moritz ML, et al. Use of C-Reactive Protein and Ferritin Biomarkers in Daily Pediatric Practice. Pediatr Rev 2020;41:172-183 
21) Horvat CM, Bell J, Kantawala S, et al. C-Reactive Protein and Ferritin Are Associated with Organ Dysfunction and Mortality in Hospitalized Children. Clin Pediatr 2019;58:752-760.

22) Goldstein B, Giroir B, Randolph A, International Consensus Conference on Pediatric Sepsis. International pediatric sepsis consensus conference definitions for sepsis and organ dysfunction in pediatrics. Pediatr Crit Care Med 2005;6:2-8

23) Villeneuve A, Joyal JS, Proulx F, et al. Multiple organ dysfunction syndrome in critically ill children: clinical value of two lists of diagnostic criteria. Ann Intens Care 2016;6:40

24) DeMerle KM, Angus DC, Baillie JK, et al. Sepsis Subclasses: A Framework for Development and Interpretation. Crit Care Med 2021;49:748-759

25) Wilkerson MD, Hayes DN. Consensus Cluster Plus: a class discovery tool with confidence assessments and item tracking. Bioinformatics 2010;26:1572-1573

26) Carcillo JA, Halstead ES, Hall MW, et al. Three Hypothetical Inflammation Pathobiology Phenotypes and Pediatric Sepsis-Induced Multiple Organ Failure Outcome. Pediatr Crit Care Med 2017; 18:513-523

27) Zou, H. \& Hastie, T. Regularization and Variable Selection via the Elastic Net. Journal of the Royal Statistical Society. Series B (Statistical Methodology) 2005; 67:301-320

28) Weiss ES, Girard-Guyonvarc'h C, Holzinger D, et al. Interleukin-18 diagnostically distinguishes and pathogenically promotes human and murine macrophage activation syndrome. Blood 2018;131:1442-1455

29)Scicluna BP, van Vught LA, Zwinderman AH, et al. Classification of patients with sepsis according to blood genomic endotype. Lancet Resp Med 2017:5:816-826 
30)Sweeney TE, Azad TD, Donato M, et al. Unsupervised analysis of transcriptomics in bacterial sepsis across multiple datasets reveals three robust clusters. Crit Care Med 2018;46:

$915-925$

31) Davenport E, Burnham KL, Radhakrishnan J, et al. Genomic landscape of the individual host response and outcomes in sepsis: a prospective cohort study. Lancet Respir Med 2016;4: 259-271

32) Zimmerman JJ, Banks R, Berg RA, et al. Life After Pediatric Sepsis Evaluation (LAPSE)

Investigators. Critical Illness Factors Associated with Long-Term Mortality and Health-Related Quality of Life Morbidity Following Community-Acquired Pediatric Septic Shock. Crit Care Med 2020;48:319-328

33) Knox DB, Lanspa MJ, Kuttler KG, Brewer SC, Brown SM. Phenotypic clusters within sepsis-associated multiple organ dysfunction syndrome. Intensive Care Med 2015 ;41:814-22

34) Ye J, Sanchez-Pinto LN. Three Data-Driven Phenotypes of Multiple Organ Dysfunction Syndrome Preserved from Early Childhood to Middle Adulthood. AMIA Annu Symp Proc 2021 ;2020:1345-1353

35) Cook A, Janse S, Watson JR, et al. Manifestations of Toxic Shock Syndrome in Children, Columbus, Ohio, USA, 2010-2017. Emerg Infect Dis. 2020;26:1077-1083

36) Ma L, Zhang YY, Yu HG. Clinical Manifestations of Kawasaki Disease Shock Syndrome. Clin Pediatr 2018;57:428-435

37) Ebato T, Ogata S, Ogihara Y, et al. The Clinical Utility and Safety of a New Strategy for the Treatment of Refractory Kawasaki Disease. J Pediatr 2017;191:140-144 
38) Godfred-Cato S, Bryant B, Leung J, et al. COVID-19-Associated Multisystem Inflammatory Syndrome in Children - United States, March-July 2020 MMWR. Morb Mortal Wkly Rep 2020;69(32):1074-1080

39) Son MBF, Murray N, Friedman K, et al. Multisystem Inflammatory Syndrome in Children Initial Therapy and Outcomes. N Engl J Med 2021;385:23-34

40) Carter MJ, Fish M, Jennings A, et al. Peripheral immunophenotypes in children with multisystem inflammatory syndrome associated with SARS-CoV-2 infection. Nat Med 2020;26(11):1701-1707

41) Chang SF, Liu SF, Chen CN, et al. Serum IP-10 and IL-17 from Kawasaki disease patients induce calcification-related genes and proteins in human coronary artery smooth muscle cells in vitro. Cell Biosci 2020;10:36

42) Szabo PA, Goswami A, Mazzuca DM, et al. Rapid and Rigorous IL-17A Production by a Distinct Subpopulation of Effector Memory T Lymphocytes Constitutes a Novel Mechanism of Toxic Shock Syndrome Immunopathology. J Immunol 2017;198:2805-2818

43) Calfee CS, Delucchi K, Parsons PE, et al. Subphenotypes in acute respiratory distress syndrome: latent class analysis of data from two randomized controlled trials. Lance Resp Med 2014:2: 611-620

44) Sinha P, Churpek MM, Calfee CS. Machine Learning Classifier Models Can Identify ARDS Phenotypes Using Readily Available Clinical Data. Am J Respir Crit Care Med 2020;202:996- 
medRxiv preprint doi: https://doi.org/10.1101/2021.12.02.21267016; this version posted December 6, 2021. The copyright holder for this preprint

(which was not certified by peer review) is the author/funder, who has granted medRxiv a license to display the preprint in perpetuity.

All rights reserved. No reuse allowed without permission.

45) Yasin S, Fall N, Brown RA, et al. IL-18 as a biomarker linking systemic juvenile idiopathic arthritis and macrophage activation syndrome. Rheumatology 2020;59:361-366 


\section{Figure Legend}

Figure 1. 24-hour Phenotype Distribution and Chord plot - In panel A, visualization of phenotypes using t-distributed stochastic neighbor embedding ( $\mathrm{t}-\mathrm{SNE}$ ) technique with phenotypes shown in color from the consensus $\mathrm{k}$ means clustering analysis visualizes distinction among four phenotypes. In panels B-E, each phenotype is highlighted separately and the ribbons connect to the different patterns of clinical variables and organ system dysfunctions on the top of the circle (Inflammation = Low Temperature, High Temperature, Max CRP, Max Ferritin; Organ Failure $=$ Total OFI; Pulmonary $=$ Pulmonary OFI, Intubation; Cardiovascular $=$ High Heart Rate, Low Systolic Blood Pressure, Cardiovascular OFI; Renal = High Creatinine, Renal OFI; Hepatic $=$ Hepatic OFI; Hematologic $=$ Low Hemoglobin, Low Platelets, Hematologic OFI; Neurologic $=$ Low Glasgow Coma Score Scale, Central Nervous System OFI). The chords connect from an individual phenotype to a category if the group mean involvement of the variables is differs from the overall mean for the entire cohort (see Table 1) specifically lower for Low Temperature, Systolic Blood Pressure, Hemoglobin, Platelets, and Glasgow Coma Scale Score, but higher for all other variables.

Figure 2. Ratio of inflammatory biomarkers according to 24-hour phenotypes - The cytokine heatmap shows the log ratio of the median biomarker values for various markers of the host response and their hierarchical cluster relationships. Red represents a greater median biomarker value for that phenotype compared with the median for the entire study cohort, whereas blue represents a lower median biomarker value compared with the median for the entire study cohort. For example, M-CSF is lower in PedSep-A than the entire study cohort, and is higher in PedSep-D than the entire study cohort. 
Figure 3. Heterogeneous survival interaction between therapy, and phenotype - Heatmap of Elastic Net Regression analysis shows the association between 14 individual therapies and their 182 combinations (total cells $=196$ ) with survival in PedSep-B, C, and D. The PedSep-A phenotype is not presented due to limited number of deaths. Blank cells have no patients. Values in each cell represent odds ratios of survival, where 1 represents no association with survival. Color in each cell represents direction of effect, where red represents mortality direction, green represents survival direction. Cells located at the diagonal are odds ratio of association from the 14 individual therapies. The other cells represent the survival odds ratio of combinations of these therapies compared to all other combinations. For example, survivors in PedSep-D phenotype are less likely to be treated with IVIG than non-survivors (red); whereas, survivors in PedSep-D are more likely to be treated with combined IVIG + methylprednisolone (green). 
medRxiv preprint doi: https://doi.org/10.1101/2021.12.02.21267016; this version posted December 6, 2021. The copyright holder for this preprint (which was not certified by peer review) is the author/funder, who has granted medRxiv a license to display the preprint in perpetuity.

All rights reserved. No reuse allowed without permission.

Table 1. Demographic and Day 1 Clinical Characteristics of the Four Phenotypes

\begin{tabular}{|c|c|c|c|c|c|}
\hline \multirow{2}{*}{ Characteristic $^{1}$} & \multirow[b]{2}{*}{ Total } & & & & \\
\hline & & PedSep-A & PedSep-B & PedSep-C & PedSep-D \\
\hline No. of patients, N (\%) & $404(100)$ & $136(34)$ & $102(25)$ & $110(27)$ & $56(14)$ \\
\hline \multicolumn{6}{|l|}{ Demographic } \\
\hline Age years* mean (SD) & $7(6)$ & $3(4)$ & $8(6)^{a}$ & $10(5)^{a, b}$ & $8(6)^{a}$ \\
\hline Male* N (\%) & $224(55.4)$ & $63(46.3)$ & $68(66.7)^{a}$ & $59(53.6)$ & $34(60.7)$ \\
\hline Female* $\mathrm{N}(\%)$ & $180(44.6)$ & $73(53.7)$ & $34(33.3)$ & $51(46.4)$ & $22(39.3)$ \\
\hline Hispanic* N (\%) & $67(16.6)$ & $28(20.6)$ & $12(11.8)$ & $23(20.9)$ & $4(7.1)$ \\
\hline Non-Hispanic* N (\%) & $323(80.0)$ & $100(73.5)$ & $86(84.3)$ & $86(78.2)$ & $51(91.1)$ \\
\hline Previous healthy* N (\%) & $180(44.6)$ & $96(70.6)^{b, c, d}$ & $28(27.5)$ & $37(33.6)$ & 19 (33.9) \\
\hline Surgery* $N(\%)$ & $49(12.1)$ & $6(4.4)$ & $19(18.6)^{\mathrm{a}}$ & $12(10.9)$ & $12(21.4)^{\mathrm{a}}$ \\
\hline \multicolumn{6}{|l|}{ Organ Dysfunction } \\
\hline SIRS criteria, mean $(S D)^{2}$ & $2.9(0.8)$ & $2.9(0.8)$ & $3.0(0.8)$ & $2.8(0.8)$ & $3(0.8)$ \\
\hline $\mathrm{OFI}^{*}$ mean $(\mathrm{SD})^{3}$ & $1.8(0.9)$ & $1.4(0.5)$ & $2.1(0.6)^{a, c}$ & $1.4(0.6)$ & $3.1(1.0)^{\mathrm{a}, \mathrm{b}, \mathrm{c}}$ \\
\hline \multicolumn{6}{|l|}{ Inflammation } \\
\hline $\mathrm{CRP} \mathrm{mg} / \mathrm{dL}^{*}$ mean $(\mathrm{SD})$ & $11.7(10.4)$ & $7.3(7.3)$ & $13.2(11.5)^{\mathrm{a}}$ & $15.2(10.4)^{a}$ & $13.1(11.2)^{\mathrm{a}}$ \\
\hline Low Temperature ${ }^{\circ} \mathrm{C}^{*}$ mean & $36.6(1.2)$ & $36.7(0.9)^{b}$ & $36.0(1.6)$ & $37.1(0.9)^{\mathrm{a}, \mathrm{b} . d}$ & $36.3(1.0)$ \\
\hline High Temperature ${ }^{\circ} \mathrm{C}^{*}$ mean & $37.8(1.3)$ & $37.8(1.1)$ & $37.4(1.3)$ & $38.3(1.2)^{\mathrm{a}, \mathrm{b}, \mathrm{d}}$ & $37.8(1.4)$ \\
\hline $\mathrm{ALC} / \mathrm{mm}^{3} *$ median (IQR) & $1.2(0.6-2.1)$ & $1.9(1.3-3.2)^{b, c, d}$ & $1.1(0.6-1.9)^{c}$ & $0.6(0.2-1.0)$ & $1.1(0.6-2.1)^{c}$ \\
\hline Ferritin $\mathrm{ng} / \mathrm{mL}^{*}$ median (IQR) & $218(98.0-625.3)$ & $125(69.8-207.8)$ & $\begin{array}{l}223(116.5- \\
544.2)^{a}\end{array}$ & $\begin{array}{l}405(176.2- \\
1485.7)^{a, b}\end{array}$ & $\begin{array}{l}610(221.1- \\
2482.0)^{a, b}\end{array}$ \\
\hline \multicolumn{6}{|l|}{ Pulmonary } \\
\hline Pulmonary OFI* N (\%) & $270(66.8)$ & $108(79.4)^{c}$ & $87(85.3)^{c}$ & $37(33.6)$ & $38(67.9)^{c}$ \\
\hline Intubation* N (\%) & $211(52.2)$ & $72(52.9)^{c}$ & $94(92.2)^{a, c, d}$ & $15(13.6)$ & $30(53.6)^{c}$ \\
\hline \multicolumn{6}{|l|}{ Cardiovascular or Hemodynamic } \\
\hline Heart rate bpm* mean (SD) & $155.4(31.3)$ & $168.1(30.8)^{b, c, d}$ & $146.5(27.9)$ & $150.4(27.6)$ & $150.6(35.8)$ \\
\hline Systolic blood pressure, ${ }^{*}$ & $81.9(19.3)$ & $85.0(15.7)^{b}$ & $74.8(22.0)$ & $86.3(17.2)^{b}$ & $78.9(21.9)$ \\
\hline mean (SD) mmHg & & & & & \\
\hline Cardiovascular OFI* N (\%) & $284(70.3)$ & $63(46.3)$ & $92(90.2)^{a}$ & $85(77.3)^{a}$ & $44(78.6)^{a}$ \\
\hline \multicolumn{6}{|l|}{ Renal } \\
\hline Creatinine $\mathrm{mg} / \mathrm{dL}^{*}$ median (IQR) & $0.5(0.3-0.8)$ & $0.3(0.2-0.4)$ & $0.6(0.4-1.0)^{a}$ & $0.6(0.4-0.7)^{a}$ & $1.4(0.6-2.6)^{\mathrm{a}, \mathrm{b}, \mathrm{c}}$ \\
\hline Renal OFI* N (\%) & $30(7.4)$ & $0(0.0)$ & $0(0.0)$ & $0(0.0)$ & $30(53.6)^{a, b, c}$ \\
\hline \multicolumn{6}{|l|}{ Hepatic } \\
\hline Hepatic OFI* N (\%) & $40(9.9)$ & $3(2.2)$ & $9(8.8)$ & $11(10.0)^{\mathrm{a}}$ & $17(30.4)^{a, b, c}$ \\
\hline
\end{tabular}


medRxiv preprint doi: https://doi.org/10.1101/2021.12.02.21267016; this version posted December 6, 2021. The copyright holder for this preprint (which was not certified by peer review) is the author/funder, who has granted medRxiv a license to display the preprint in perpetuity.

All rights reserved. No reuse allowed without permission.

\begin{tabular}{|c|c|c|c|c|c|}
\hline \multicolumn{6}{|l|}{ Hematologic } \\
\hline Hemoglobin $\mathrm{g} / \mathrm{dL} *$ mean $(\mathrm{SD})$ & $9.8(2.0)$ & $10.1(1.8)^{b, d}$ & $9.4(2.1)$ & $10.2(2.1)^{b, d}$ & $9.1(1.8)$ \\
\hline Platelets $\mathrm{K} / \mathrm{mm}^{3} *$ mean (SD) & $171.1(123.2)$ & $260.1(122.0)^{b, c, d}$ & $154.3(95.1)^{c, d}$ & $118.8(83.5)^{d}$ & $88.2(108.0)$ \\
\hline Hematologic OFI* N (\%) & $39(9.7)$ & $0(0.0)$ & $0(0.0)$ & $8(7.3)^{a, b}$ & $31(85.7)^{a, b, c}$ \\
\hline \multicolumn{6}{|l|}{ Neurologic } \\
\hline Glasgow Coma Scale score* & $8.7(5.3)$ & $8.5(5.2)^{b}$ & $4.7(3.4)$ & $13.2(3.1)^{\mathrm{a}, \mathrm{b}, \mathrm{d}}$ & $7.9(5.5)^{\mathrm{b}}$ \\
\hline \multicolumn{6}{|l|}{ mean $(S D)^{4,5}$} \\
\hline CNS OFI N (\%) & $54(13.4)$ & $12(8.8)$ & $24(23.5)^{a, c}$ & $6(5.5)$ & $12(21.4)^{c}$ \\
\hline
\end{tabular}

Abbreviations: IQR, interquartile range; SIRS, systemic inflammatory response syndrome; OFI, organ failure index;

ALC, absolute lymphocyte count; CNS, central nervous system

SI conversion factors: To convert alanine transaminase and aspartate aminotransferase to $\mu$ kat/L, multiply by

0.0167; bilirubin to $\mu \mathrm{mol} / \mathrm{L}$, multiply by 17.104 ; C-reactive protein to $\mathrm{nmol} / \mathrm{L}$, multiply by 9.524 ; creatinine

to $\mu \mathrm{mol} / \mathrm{L}$, multiply by 88.4 .

${ }^{1}$ The variables in this Table were log transformed for modeling (eTable 3 in the Supplement). Comparisons across all 4 phenotypes were performed using the Kruskal-Wallis test, the $\chi 2$ test, or the fisher's exact test (eTable 3 in the Supplement. $\mathrm{P}<.05$ for all comparisons after adjustment).

${ }^{2}$ Indicates SIRS criteria ranging from 0 to 4 including abnormal heart rate, respiratory rate, temperature, and white blood cell count.

${ }^{3} \mathrm{OFI}$ is an integer score reflecting the number of organ failures. Scores are either 0 or 1 for cardiovascular, hepatic, hematologic, respiratory, neurological, and renal, and summed for total range of 0 to 6 . Cardiovascular, need for cardiovascular agent infusion support; Pulmonary, need for mechanical ventilation support with the ratio of the arterial partial pressure of oxygen and the fraction of inspired oxygen $(\mathrm{PaO} 2 / \mathrm{FiO} 2)<300$ without this support; Hepatic, total bilirubin $>1.0 \mathrm{mg} / \mathrm{dL}$ and alanine aminotransferase $(\mathrm{ALT})>100$ units/L; Renal, serum creatinine $>1.0$ $\mathrm{mg} / \mathrm{dL}$ and oliguria (urine output $<0.5 \mathrm{~mL} / \mathrm{kg} / \mathrm{hr}$ ); Hematologic, thrombocytopenia $<100,000 / \mathrm{mm}^{3}$ and 
medRxiv preprint doi: https://doi.org/10.1101/2021.12.02.21267016; this version posted December 6, 2021. The copyright holder for this preprint

(which was not certified by peer review) is the author/funder, who has granted medRxiv a license to display the preprint in perpetuity.

All rights reserved. No reuse allowed without permission.

prothrombin time INR $>1.5 \times$ normal; Central Nervous System, Glasgow Coma Scale (GCS) score $<12$ in absence of sedatives.

${ }^{4}$ Corresponds to minimum or maximum value (as appropriate) within 6 hours of hospital presentation.

${ }^{5} \mathrm{GCS}$ ranges from 3 to 15 .

${ }^{\mathrm{a}}$ The outcome characteristic of this computable phenotype is significantly higher than PedSep-A ( $p$-value $\left.<0.05\right)$

${ }^{b}$ The outcome characteristic of this computable phenotype is significantly higher than PedSep-B (p-value $\left.<0.05\right)$

${ }^{\mathrm{C}}$ The outcome characteristic of this computable phenotype is significantly higher than PedSep-C (p-value $\left.<0.05\right)$

${ }^{\mathrm{d}}$ The outcome characteristic of this computable phenotype is significantly higher than PedSep-D (p-value $\left.<0.05\right)$

${ }^{*}$ Comparisons across all 4 computable phenotypes were performed using the Kruskal-Wallis test, the $\chi 2$ test, or the fisher's exact test (eTable3, $\mathrm{P}<.05$ for all comparisons after adjustment). 
medRxiv preprint doi: https://doi.org/10.1101/2021.12.02.21267016; this version posted December 6, 2021. The copyright holder for this preprint (which was not certified by peer review) is the author/funder, who has granted medRxiv a license to display the preprint in perpetuity.

Table 2. Subsequent Outcome Characteristics of the Four Phenotypes

\begin{tabular}{|c|c|c|c|c|c|}
\hline \multirow{2}{*}{ Characteristic $^{e}$} & \multirow[b]{2}{*}{ Total } & & & & \\
\hline & & PedSep-A & PedSep-B & PedSep-C & PedSep-D \\
\hline No. of patients, $\mathrm{N}(\%)$ & $404(100)$ & $136(34)$ & $102(25)$ & $110(27)$ & $56(14)$ \\
\hline \multicolumn{6}{|c|}{ Development of Subsequent MOF Empirical Phenotypes } \\
\hline SMOF, N (\%) & $7(1.7)$ & $0(0.0)$ & $0(0.0)$ & $1(0.9)$ & $6(10.7)^{a, b, c}$ \\
\hline TAMOF, N (\%) & $37(9.2)$ & $0(0.0)$ & $6(5.9)^{\mathrm{a}}$ & $3(2.7)$ & $28(50.0)^{a, b, c}$ \\
\hline IPMOF, N (\%) & $85(21.0)$ & $12(8.8)$ & $29(28.4)^{\mathrm{a}}$ & $22(20)$ & $22(39.3)^{\mathrm{a}}$ \\
\hline MAS, N (\%) & $24(5.5)$ & $0(0.0)$ & $3(2.9)$ & $2(1.8)$ & $19(33.9)^{a, b, c}$ \\
\hline NPMOF, N (\%) & $117(29.0)$ & $28(20.6)$ & $25(24.5)$ & $32(29.1)$ & $32(57.1)^{a, b, c}$ \\
\hline \multicolumn{6}{|l|}{ Infections } \\
\hline Bacterial infection, $\mathrm{N}(\%)$ & $141(34.9)$ & $43(31.6)$ & $33(32.4)$ & 45 (40.9) & $20(35.7)$ \\
\hline Viral infection, $\mathrm{N}(\%)$ & $114(28.2)$ & $60(44.1)^{b, c, d}$ & 21 (20.6) & $24(21.8)$ & $9(16.1)$ \\
\hline Fungal infection, $\mathrm{N}(\%)$ & $4(1.0)$ & $0(0.0)$ & $1(1.0)$ & $0(0.0)$ & $3(5.4)$ \\
\hline Culture negative, $\mathrm{N}(\%)$ & $177(43.8)$ & $47(34.6)$ & $52(51.0)$ & $50(45.5)$ & $28(50.0)$ \\
\hline \multicolumn{6}{|l|}{ Sites of Infections ${ }^{f}$} \\
\hline Blood, N (\%) & $51(12.6)$ & $10(7.4)$ & $6(5.9)$ & $22(20.0)^{a, b}$ & $13(23.2)^{a, b}$ \\
\hline Lung, N (\%) & $76(18.8)$ & $28(20.6)$ & $29(28.4)^{a, c, d}$ & $12(10.9)$ & $7(12.5)$ \\
\hline Urine, N (\%) & $16(4.0)$ & $4(2.9)$ & $5(4.9)$ & $6(5.5)$ & $1(1.8)$ \\
\hline \multicolumn{6}{|l|}{ Organ Support } \\
\hline MechVent, N (\%) & $366(90.6)$ & $134(98.5)^{c}$ & $101(99.0)^{c}$ & $79(71.8)$ & $52(92.9)^{c}$ \\
\hline ECMO, N (\%) & $30(7.4)$ & $5(3.7)$ & $9(8.8)$ & $6(5.5)$ & $10(17.9)^{\mathrm{a}}$ \\
\hline CRRT, N (\%) & $52(12.9)$ & $1(0.7)$ & $7(6.9)$ & $7(6.4)$ & $37(66.1)^{a, b, c}$ \\
\hline \multicolumn{6}{|c|}{ Anti-inflammatory Therapies of Interest } \\
\hline Decadron, $N(\%)$ & $94(23.3)$ & $50(36.8)^{c, d}$ & $22(21.6)$ & $14(12.7)$ & $8(14.3)$ \\
\hline
\end{tabular}


medRxiv preprint doi: https://doi.org/10.1101/2021.12.02.21267016; this version posted December 6, 2021. The copyright holder for this preprint (which was not certified by peer review) is the author/funder, who has granted medRxiv a license to display the preprint in perpetuity.

All rights reserved. No reuse allowed without permission.

\begin{tabular}{|c|c|c|c|c|c|}
\hline Methylprednisone, N (\%) & $117(29.0)$ & $54(39.7)^{b}$ & $23(22.5)$ & $24(21.8)$ & $16(28.6)$ \\
\hline IVIG, N (\%) & $51(12.6)$ & $6(4.4)$ & $10(9.8)$ & $19(17.3)^{a}$ & $16(28.6)^{a}$ \\
\hline Plasma exchange, $\mathrm{N}(\%)$ & $25(6.2)$ & $5(3.7)$ & $4(3.9)$ & $4(3.6)$ & $12(21.4)^{a, b, c}$ \\
\hline \multicolumn{6}{|l|}{ Outcome } \\
\hline Length of Stay, & $9.0(5.0-17)$. & $9.0(5.8-15)^{c}$ & $10.5(5.3-17)^{c}$ & $6(2.3-15)$ & $12.5(7-26.5)^{c}$ \\
\hline \multicolumn{6}{|l|}{ median (IQR), d } \\
\hline Mortality, N (\%) & 45 (11.1) & $3(2.2)$ & $12(11.7)^{\mathrm{a}}$ & $11(10.0)^{\mathrm{a}}$ & $19(33.9)^{a, b, c}$ \\
\hline
\end{tabular}

Abbreviations: SMOF, sequential liver failure associated multiple organ failure; TAMOF, thrombocytopenia associated multiple organ failure; IPMOF, immunoparalysis associated multiple organ failure; MAS, macrophage activation syndrome; NPMOF, new or progressive multiple organ failure; IQR, interquartile range; MechVent, Mechanical Ventilation; ECMO, Extracorporeal Membrane Oxygenation; CRRT, Continuous Renal Replacement Therapies; IVIG, intravenous gamma globulin

${ }^{a}$ The outcome characteristic of this computable phenotype is significantly higher than PedSep-A ( $p$-value $\left.<0.05\right)$

${ }^{b}$ The outcome characteristic of this computable phenotype is significantly higher than PedSep-B (p-value $\left.<0.05\right)$

${ }^{\mathrm{c}}$ The outcome characteristic of this computable phenotype is significantly higher than PedSep-C (p-value $\left.<0.05\right)$

${ }^{d}$ The outcome characteristic of this computable phenotype is significantly higher than PedSep-D (p-value $<0.05$ )

${ }^{\mathrm{e}}$ Comparisons across all 4 computable phenotypes were performed using the Kruskal-Wallis test, the $\chi 2$ test, or the fisher's exact test (eTable3, $\mathrm{P}<.05$ for all comparisons after adjustment).

${ }^{f}$ Obtained at the first 3 days 
medRxiv preprint doi: https://doi.org/10.1101/2021.12.02.21267016; this version posted December 6, 2021. The copyright holder for this preprint (which was not certified by peer review) is the author/funder, who has granted medRxiv a license to display the preprint in perpetuity.

All rights reserved. No reuse allowed without permission.

Figure 1. 24-hour Phenotype Distribution and Chord plot

A t-SNE Plot of Phenotype Assignments $(n=404)$

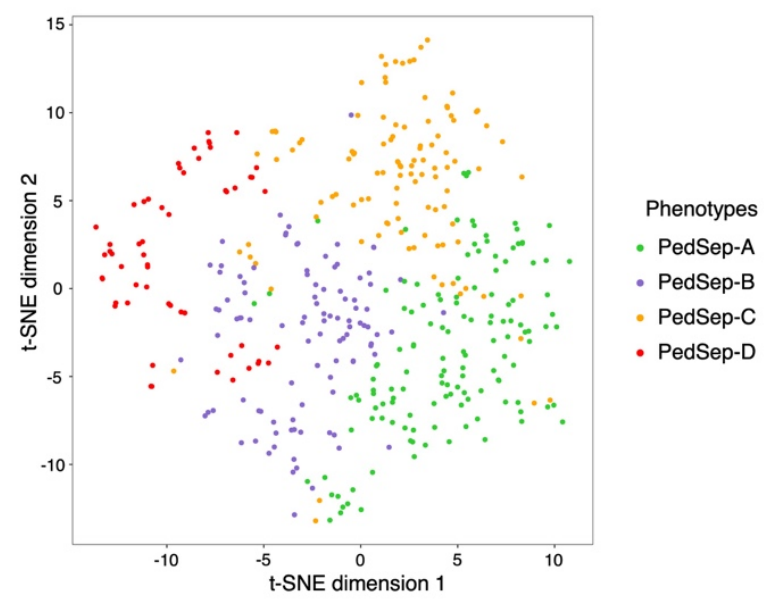

B PedSep-A Phenotype

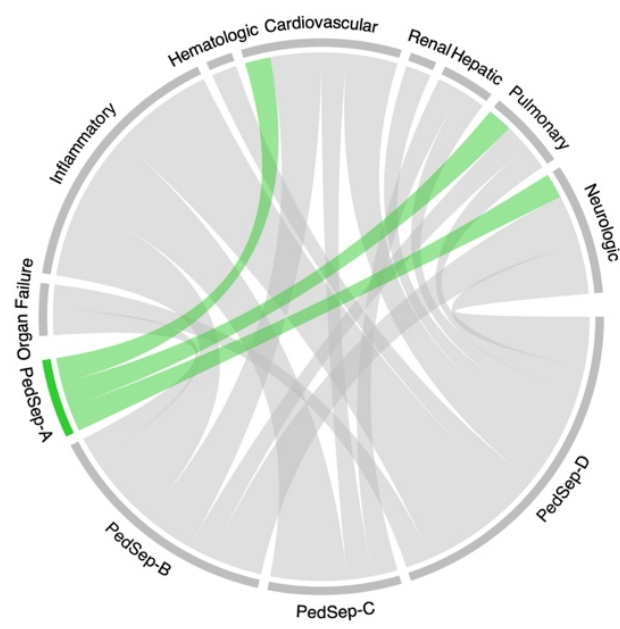

D PedSep-C Phenotype

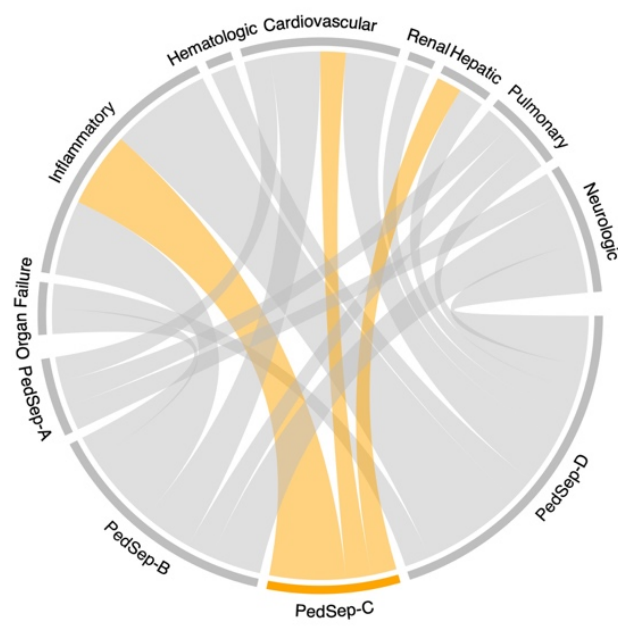

C PedSep-B Phenotype

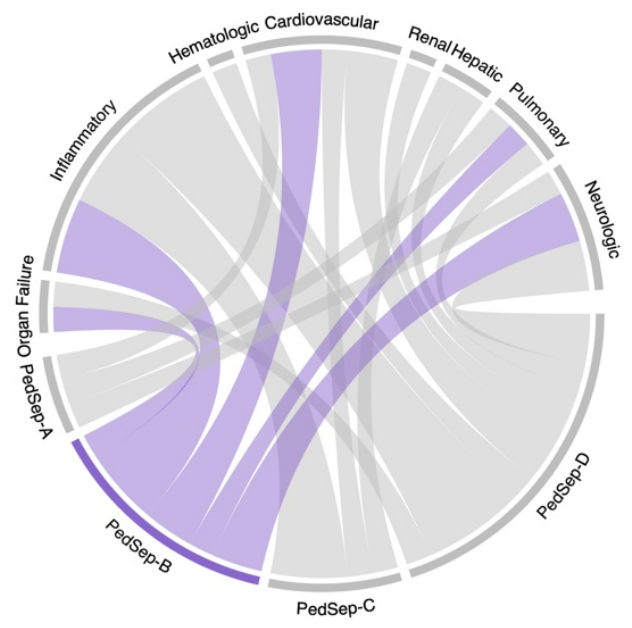

E PedSep-D Phenotype

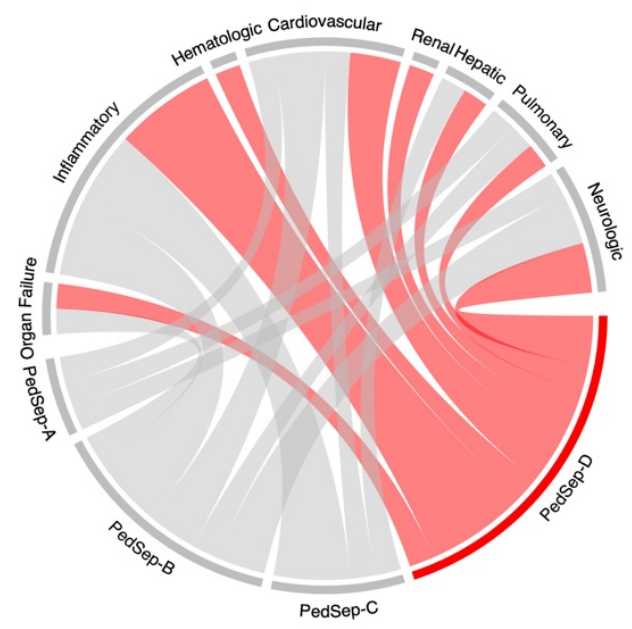


medRxiv preprint doi: https://doi.org/10.1101/2021.12.02.21267016; this version posted December 6, 2021. The copyright holder for this preprint (which was not certified by peer review) is the author/funder, who has granted medRxiv a license to display the preprint in perpetuity.

All rights reserved. No reuse allowed without permission.

Figure 2. Ratio of inflammatory biomarkers according to 24-hour phenotypes

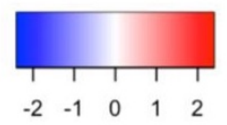

Log (Ratio with whole population)
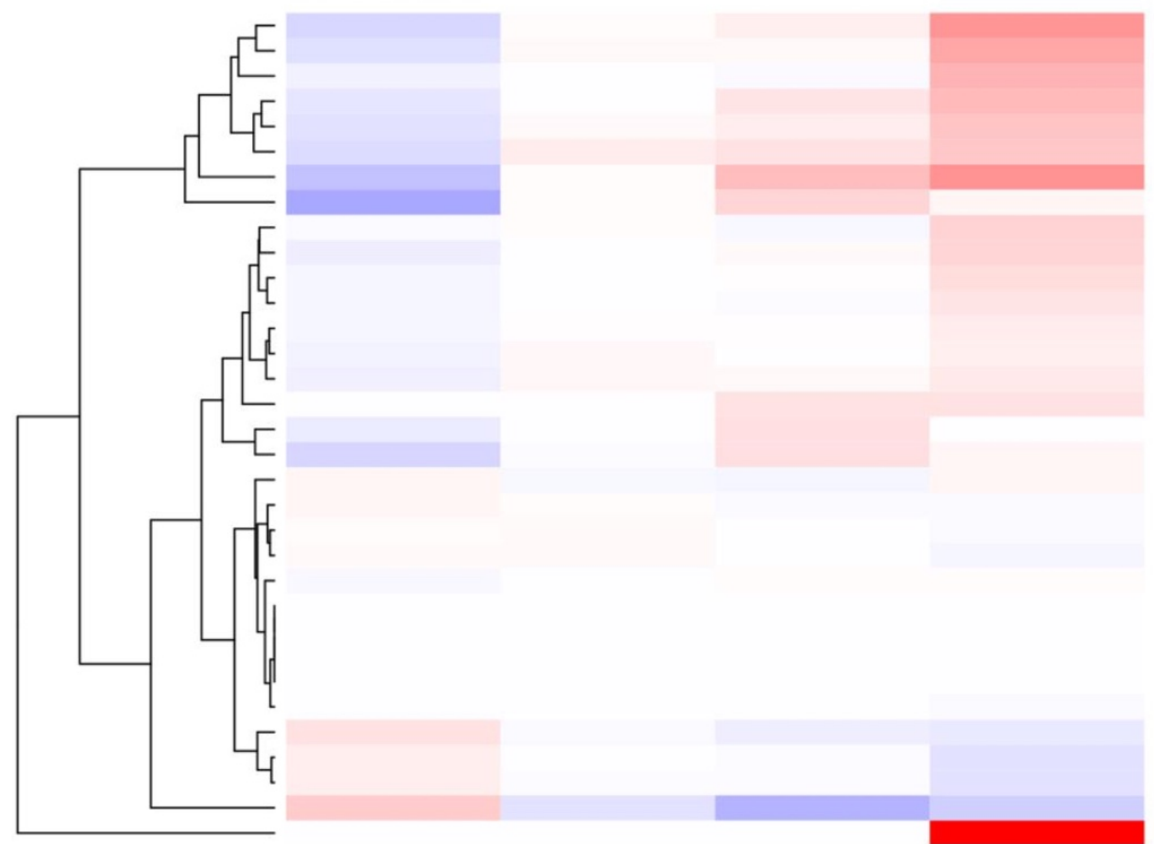

M-CSF

IL-8

$\mathrm{SCF}$

IL-6

SCD163

MCP-1/CCL2

CRPH

IL-16

IL-16

TNF-a

MIP-1 $\beta$

IL-2RA

IL-18

IL-22

MCP-3

IL-17A

IP-10/CXCL10

IL-18BP

$\mathrm{MIG} / \mathrm{CXCL9}$

IL-3

IL-4
IL-1 $\beta$

IL-13

IFN- $\beta$

IFN-Y

IL-1a

IFN-a2

sFasLg
ADAMTS13

TRAIL

Ex vivo TNF-a

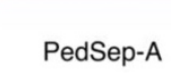

PedSep-B

PedSep-C

PedSep-D

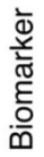

Phenotype 
medRxiv preprint doi: https://doi.org/10.1101/2021.12.02.21267016; this version posted December 6, 2021. The copyright holder for this preprint (which was not certified by peer review) is the author/funder, who has granted medRxiv a license to display the preprint in perpetuity.

All rights reserved. No reuse allowed without permission.

Figure 3. Heterogeneous survival interaction between therapy, and phenotype

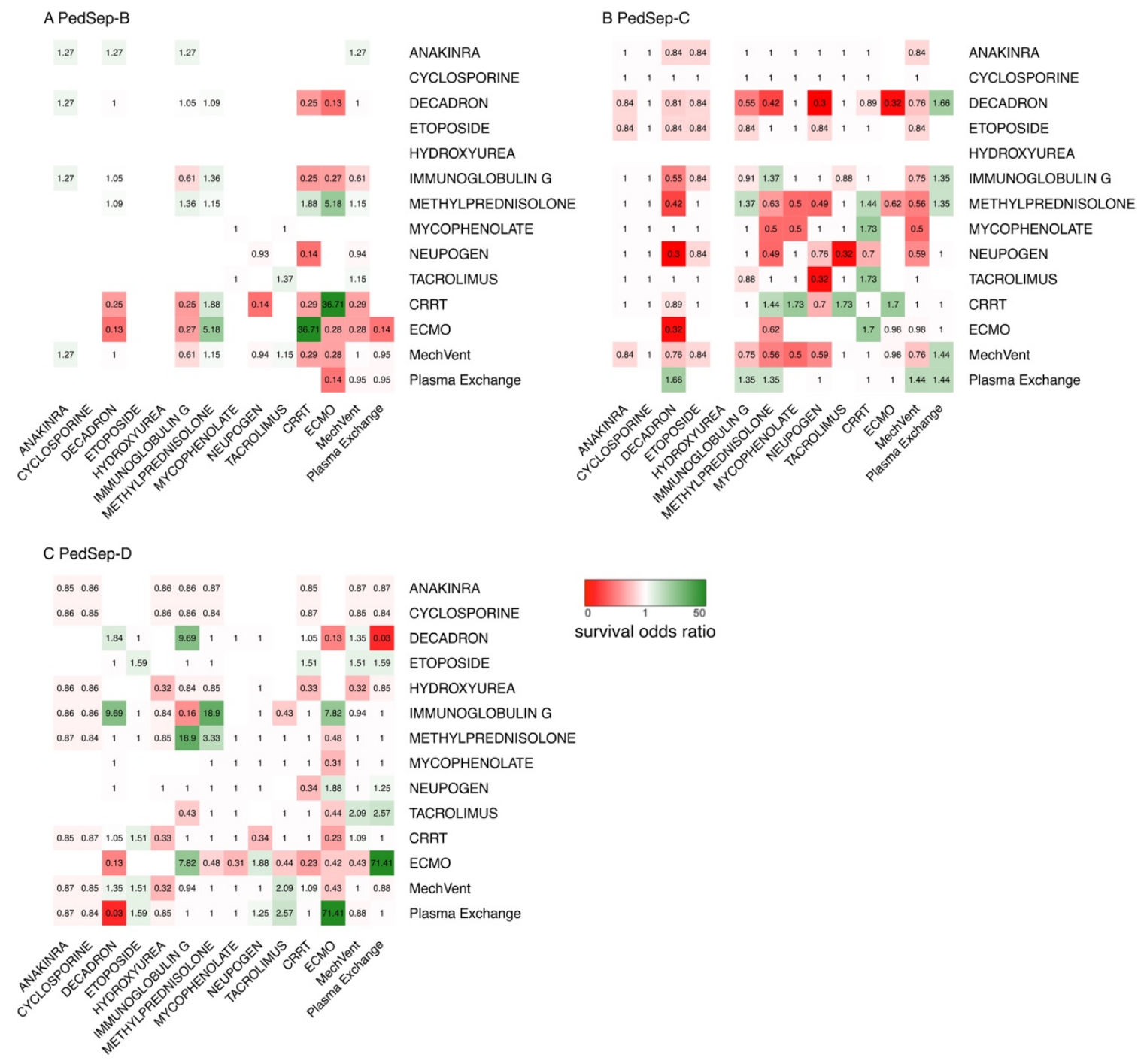

